\title{
Preventive Effect of Intraoperative Landiolol Administration on Atrial Fibrillation After Off-Pump Coronary Artery Bypass Grafting
}

\author{
Masahiro Osumi · Tadashi Tashiro $\cdot$ Yuichi Morita $\cdot$ Shinji Kamiya • \\ Noritoshi Minematsu $\cdot$ Masaru Nishimi $\cdot$ Hideichi Wada
}

To view enhanced content go to www.advancesintherapy.com

Received: September 1, 2014 / Published online: October 16, 2014

(c) The Author(s) 2014. This article is published with open access at Springerlink.com

\section{ABSTRACT}

Introduction: Postoperative atrial fibrillation (AF) is a common complication of cardiac surgery that is associated with an increased incidence of other complications. This study evaluated the safety and efficacy of landiolol hydrochloride-an ultrashort-acting $\quad \beta 1$ selective blocker and highly regulated drug, positioned as a class 1 antiarrhythmic in Japan guidelines-for the prevention of AF after offpump coronary artery bypass grafting (CABG).

Methods: Between January 2011 and November 2013, 116 patients underwent CABG at Fukuoka University Hospital. They were divided into two groups: group L consisted of patients who were administered landiolol hydrochloride at $2 \mu \mathrm{g} /$ $\mathrm{kg} / \mathrm{min}$ after completion of all distal anastomoses; group C was the control group

Electronic supplementary material The online version of this article (doi:10.1007/s12325-014-0158-0) contains supplementary material, which is available to authorized users.

M. Osumi (凶) · T. Tashiro · Y. Morita - S. Kamiya .

N. Minematsu $\cdot$ M. Nishimi $\cdot$ H. Wada

Department of Cardiovascular Surgery, Fukuoka

University Faculty of Medicine, 7-45-1 Nanakuma,

Jonan-ku, Fukuoka 814-0133, Japan

e-mail: mosumi@fukuoka-u.ac.jp consisting of patients who were not administered landiolol. Patient backgrounds, intraoperative variables and incidence of postoperative complications were compared.

Results: No significant between-group differences were observed in patient backgrounds or incidence of complications other than postoperative $\mathrm{AF}$, which occurred significantly less frequently in group L. After administration of landiolol, heart rate decreased but no change was observed in arterial pressure or other parameters, and patient hemodynamics remained stable.

Conclusion: Intraoperative and perioperative administration of low-dose landiolol has a preventive effect on the development of $\mathrm{AF}$ after CABG surgery.

Keywords: Atrial fibrillation; $\beta$-Blocker; Coronary artery bypass graft; Landiolol;

ONO-1101

\section{INTRODUCTION}

Atrial fibrillation (AF) is the most common dysrhythmia occurring following cardiac surgery and may cause embolism or stroke, 
longer intensive care unit and total hospital stays, and increased health care costs [1-5]. Various guidelines [6-8] strongly recommend treatment with a $\beta$-blocker to prevent postoperative $\mathrm{AF}$ in patients undergoing cardiac surgery because the appearance of AF during the perioperative period increases myocardial oxygen consumption and may cause deterioration of a patient's hemodynamics. Furthermore, AF is considered a risk factor for myocardial ischemia because the shortened left ventricular diastolic time decreases coronary artery blood flow [9]. In many cases, postoperative $\mathrm{AF}$ is transient and reverts spontaneously to sinus rhythm, but tachycardia due to prolonged AF may impair left ventricular function and cause congestive heart failure. Therefore, it is particularly important to control tachyarrhythmia during the perioperative period in cases of coronary artery bypass grafting (CABG). Landiolol hydrochloride (Ono Pharmaceutical Co, Ltd., Osaka, Japan), a highly regulated, ultrashortacting $\beta$-blocker, was developed in Japan as a drug with a short half-life and very high $\beta 1$ selectivity. It was hypothesized that the superior pharmacological profile of landiolol would enable safer use in patients in the acute phase of severe heart disease and in other clinical settings [10] and would reduce the development of postoperative AF. Therefore, we performed a retrospective, single-institution study to determine if intraoperative administration of landiolol reduces the incidence of AF after cardiac surgery.

\section{METHODS}

We reviewed the records of 250 consecutive patients who underwent CABG surgery between January 2011 and November 2013 at our institution. Patients with previous permanent or persistent $\mathrm{AF}$ or a permanent pacemaker were excluded from the analysis. One hundred and sixteen patients met these criteria. Landiolol was administered to 41 patients from January 2011 to November 2013 (group L), and this group of patients was compared with a control group of 75 patients who were not administered landiolol (group C) during the same period. Use of landiolol was decided by anesthesiologists, who declined to use landiolol in patients who had hemodynamic instability. Those with a systolic blood pressure (SBP) $<80 \mathrm{mmHg}$ were treated with landiolol at the discretion of the anesthesiologist.

The administration of landiolol was initiated at $2 \mu \mathrm{g} / \mathrm{kg} / \mathrm{min}(\gamma)$ after completion of the distal anastomoses. It was increased in increments of $\gamma$, titrating to a target heart rate (HR) of 80 beats/min. The minimum dose was $\gamma$, and this dose was used during the intensive care unit (ICU) stay. The criterion for discontinuation of treatment was excessive reduction in systolic blood pressure (SBP) to $<80 \mathrm{mmHg}$ or in heart rate (HR) to less than 60 beats/min that did not improve with inotropic agents.

Patients were continuously monitored using alarm-triggered bedside monitors during the first $48 \mathrm{~h}$ after surgery and continuous Holter monitoring with three-lead, alarm-triggered telemetry systems until postoperative day 7 . Postoperative AF was observed via continuous electrocardiographic monitoring or a 12-lead electrocardiogram. AF was defined as an absence of $\mathrm{P}$ waves before QRS complexes that continued for $30 \mathrm{~min}$ and the presence of an irregular heartbeat. Persistence of electrocardiographic changes for $<30 \mathrm{~min}$ but requiring treatment, such as further administration of antiarrhythmic drugs and 
countershock, was also considered postoperative AF.

Univariate analysis of factors associated with the occurrence of postoperative AF was performed using a logistic regression model. IBM SPSS Statistics for Windows, Version 19.0 (IBM Corp., Armonk, NY, USA), was used for all analyses.

All procedures followed were in accordance with the ethical standards of the responsible committee on human experimentation (institutional and national) and with the Helsinki Declaration of 1975, as revised in 2000 and 2008. Informed consent was obtained from all patients for being included in the study.

\section{RESULTS}

Patients' preoperative characteristics are listed in Tables 1 and 2. Mean age was $69.46 \pm 1.56$ years in group $\mathrm{L}$ and $67.25 \pm 0.97$ years in group $C$, with females constituting $19.5 \%$ and $16.0 \%$ of patients, respectively. There were no significant differences in preoperative characteristics or intraoperative data, or with respect to the number of diseased vessels, left ventricular ejection fraction or European System for Cardiac Operative Risk Evaluation (EuroSCORE) [11]. Intraoperative variables are listed in Table 3. No significant between-group differences were observed in operative duration or number of distal coronary anastomoses. Hospital death was not observed in either group (Tables 4, 5). The incidences of major complications, except postoperative $\mathrm{AF}$, were equivalent in the two groups; the incidence of postoperative AF was significantly lower in group $\mathrm{L}$ than in group C $(12.2 \%$ versus $30.67 \%, P=0.0263)$.
Measurements of SBP, HR, cardiac index (CI), and systemic vascular resistance index (SVRI) for both groups intraoperatively and at postoperative day 1 are shown Fig. 1 . There were no between-group differences in hemodynamic parameters at any time point. However, SBP significantly increased in both groups, and significant decreases were seen in HR $(P<0.05)$ and CI $(P<0.05)$ in group L. We used preoperative and postoperative oral medication ( $\beta$-blocker), sex, age, body surface area, and left ventricular ejection fraction as variables in our analysis, and significant differences were associated with the administration of landiolol $(P=0.026)$, as listed in Table 6.

Postoperative AF occurred in 12.2\% of patients in group L and $30.7 \%$ of patients in group $\mathrm{C}(\log \operatorname{rank} P=0.0463)$ (Fig. 2); a difference significantly associated with the use of landiolol.

\section{DISCUSSION}

Landiolol is a novel ultrashort-acting $\beta$-blocker that has a plasma half-life of 4 min [12]. In a recent randomized controlled study, Sezai et al. [13] reported that landiolol administration significantly reduced heart rate and the occurrence of AF in post-cardiac surgery patients without a significant change in blood pressure. Another prospective multi-center randomized study of landiolol in adult patients (JL-KNIGHT) [14] was recently undertaken in Japan. This drug has been widely used in Japan and has higher $\beta 1$ selectivity than any currently available $\beta$-blocker, but has neither intrinsic sympathomimetic activity nor significant membrane-stabilizing activity [15-18]. However, until now little information on the 
Table 1 Preoperative patient characteristics

\begin{tabular}{llll}
\hline & Group C $(\boldsymbol{n}=\mathbf{7 5})$ & Group L $(\boldsymbol{n}=\mathbf{4 1})$ & $\boldsymbol{P}$ value \\
\hline Mean age (years) & $67.25 \pm 0.97$ & $69.46 \pm 1.56$ & 0.2090 \\
Age $>70$ years $(n)$ & $36(48.0 \%)$ & $20(48.8 \%)$ & 0.9336 \\
Female sex & $12(16.0 \%)$ & $8(19.5 \%)$ & 0.6357 \\
Body surface area $\left(\mathrm{m}^{2}\right)$ & $1.65 \pm 0.02$ & $1.61 \pm 0.03$ & 0.2741 \\
OMI & $15(20.0 \%)$ & $6(14.6 \%)$ & 0.4774 \\
LVEF $(\%)$ & $58.27 \pm 1.69$ & $55.72 \pm 2.37$ & 0.3768 \\
EF $<40 \%(n)$ & $9(12.0 \%)$ & $9(22.0 \%)$ & 0.1598 \\
Number of diseased vessels & $2.76 \pm 0.05$ & $2.81 \pm 0.09$ & 0.6642 \\
LMT $>50 \%$ & $23(30.7 \%)$ & $16(39.0 \%)$ & 0.3667 \\
$\beta$-Blocker & $14(18.7 \%)$ & $7(17.1 \%)$ & 0.8331 \\
\hline
\end{tabular}

Data presented as mean \pm standard deviation unless otherwise indicated

$C$ control, $E F$ ejection fraction, $L$ landiolol, $L M T$ left main trunk, $L V E F$ left ventricular ejection fraction, $O M I$ old myocardial infarction

Table 2 Preoperative patient characteristics

\begin{tabular}{llll}
\hline & Group C $(\boldsymbol{n}=75)$ & Group L $(\boldsymbol{n}=\mathbf{4 1})$ & $\boldsymbol{P}$ value \\
\hline Hypertension & $59(78.70 \%)$ & $37(90.20 \%)$ & 0.1116 \\
Hyperlipidemia & $42(56.00 \%)$ & $24(58.50 \%)$ & 0.7924 \\
Diabetes mellitus & $47(62.70 \%)$ & $27(65.90 \%)$ & 0.7355 \\
Peripheral arterial disease & $7(9.33 \%)$ & $4(9.75 \%)$ & 0.9414 \\
Chronic renal failure (creatinine $>1.5)$ & $14(18.70 \%)$ & $5(12.20 \%)$ & 0.3723 \\
EuroSCORE (standard) & $4.69 \pm 0.35$ & $4.12 \pm 0.43$ & 0.8587 \\
\hline
\end{tabular}

Data presented as $n(\%)$ or mean \pm standard deviation

$C$ control, EuroSCORE European System for Cardiac Operative Risk Evaluation, $L$ landiolol

efficacy of intraoperative landiolol use in patients undergoing cardiac surgery has been available.

$\mathrm{AF}$ is one of the most frequent complications following cardiac surgery, occurring in $25 \%$ to $40 \%$ of cases [1]. Postoperative AF has been shown to result from thromboembolism, and it leads to extended ICU and hospital stays and increased medical costs [2-5]. Moreover, tachyarrhythmia, of which the most common type is AF, increases myocardial oxygen consumption [19]. Previous studies have reported that postoperative AF increases the incidence of postoperative pneumonia, myocardial infarction and heart failure and, consequently, mortality. It is also considered a risk factor for myocardial ischemia because a shortened left ventricular diastolic time decreases coronary artery blood flow [20]. The utility of landiolol in preventing postoperative 
Table 3 Intraoperative variables

\begin{tabular}{llll}
\hline & Group C $(\boldsymbol{n}=\mathbf{7 5})$ & Group L $(\boldsymbol{n}=\mathbf{4 1})$ & $\boldsymbol{P}$ value \\
\hline Operative duration $(\mathrm{h})$ & $5.93 \pm 0.11$ & $5.76 \pm 0.19$ & 0.4510 \\
Scheduled IABP $(n)$ & $11(14.7 \%)$ & $11(26.8 \%)$ & 0.1121 \\
Number of distal anastomoses & $4.23 \pm 0.12$ & $3.81 \pm 0.25$ & 0.1111 \\
LITA & $73(97.3 \%)$ & $41(100.0 \%)$ & 0.2956 \\
RITA & $23(30.7 \%)$ & $12(29.3 \%)$ & 0.8767 \\
RA & $37(49.3 \%)$ & $18(43.9 \%)$ & 0.5794 \\
SVG & $67(89.3 \%)$ & $39(95.1 \%)$ & 0.2924 \\
Dopamine $(\mu \mathrm{g} / \mathrm{kg} / \mathrm{min})$ & $5.19 \pm 0.21$ & $5.18 \pm 0.26$ & 0.9732 \\
\hline
\end{tabular}

Data presented as $n(\%)$ or mean \pm standard deviation

$C$ control, $I A B P$ intra-aortic balloon pump, $L$ landiolol, LITA left internal thoracic artery, $R A$ renal artery, $R I T A$ right internal thoracic artery, $S V G$ saphenous vein graft

Table 4 Postoperative variables

\begin{tabular}{llll}
\hline & Group C $(\boldsymbol{n}=\mathbf{7 5})$ & Group L $(\boldsymbol{n}=\mathbf{4 1})$ & $\boldsymbol{P}$ value \\
\hline Intensive care unit stay (days) & $2.57 \pm 0.27$ & $2.83 \pm 0.38$ & 0.5855 \\
Intubation time (h) & $22.1 \pm 3.81$ & $18.4 \pm 2.52$ & 0.5140 \\
Hospital stay (days) & $18.8 \pm 0.84$ & $18.0 \pm 0.98$ & 0.6145 \\
\hline
\end{tabular}

Data presented as mean \pm standard deviation

$C$ control, $L$ landiolol

Table 5 Perioperative variables

\begin{tabular}{lccc}
\hline & Group C $(\boldsymbol{n}=\mathbf{7 5})$ & Group L $(\boldsymbol{n}=\mathbf{4 1})$ & $\boldsymbol{P}$ value \\
\hline Atrial fibrillation & $23(30.67 \%)$ & $5(12.20 \%)$ & 0.0263 \\
Perioperative stroke & $1(13.30 \%)$ & $0(0.00 \%)$ & 0.4621 \\
30 -day mortality & $0(0.00 \%)$ & $0(0.00 \%)$ & - \\
\hline
\end{tabular}

$C$ control, $L$ landiolol

AF has been widely reported. Previous studies using $\beta$-blockers or amiodarone have reported significant reductions in postoperative $\mathrm{AF}$ compared with placebo; however, the incidence varied widely, from $3 \%$ to $34 \%$ [21, 22].

In this study, among the factors previously considered risk factors for postoperative $\mathrm{AF}$ (including advanced age, male sex, body surface area and $\beta$-blocker use), we found age and landiolol administration to be inhibitory. Postoperative AF was observed in only five patients in group L. Peak incidence of postoperative AF occurred in the first 2-3 days following CABG. We note, however, that not only was AF significantly inhibited during the administration of landiolol, but its occurrence 

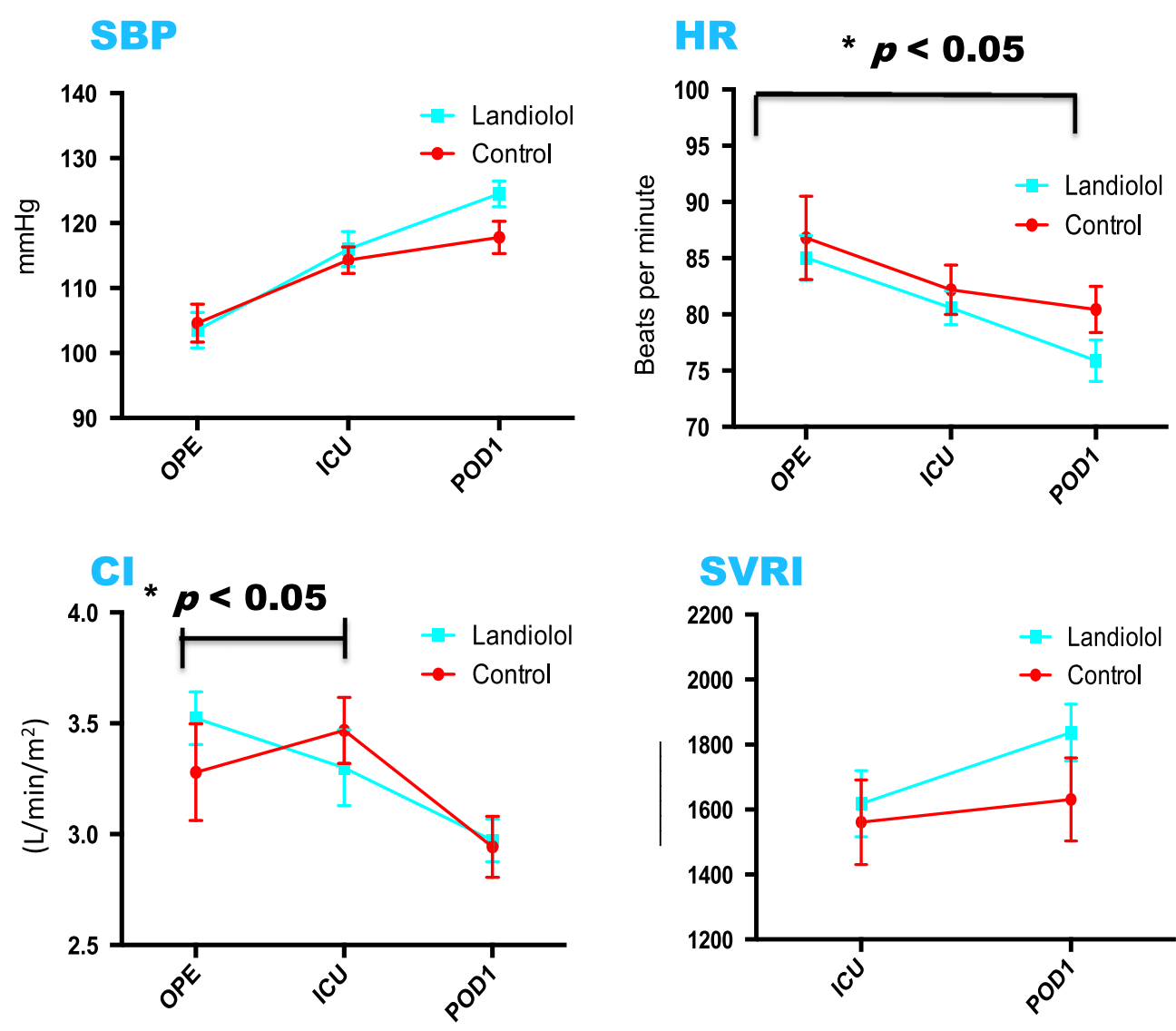

Fig. 1 Measurements of systolic blood pressure, heart rate, cardiac index and systemic vascular resistance index for both groups intraoperatively and at postoperative day 1 . CI

within 1 week of surgery was also reduced. Because the half-life of the drug is short, the reason for its effect after discontinuation is unknown, as is the mechanism for inhibiting AF within 1 week, but we believe that the ability of the drug to decrease HR during the acute period and consequently stabilize hemodynamics leads to the inhibition of postoperative AF.

We believe landiolol to have a stabilizing effect during the perioperative period. However, in the present study, the safety of landiolol and the suitability of the current method of administration were studied only with regard to intraoperative administration. We believe this $\beta$-blocker can be safe and effective if appropriate administration methods are

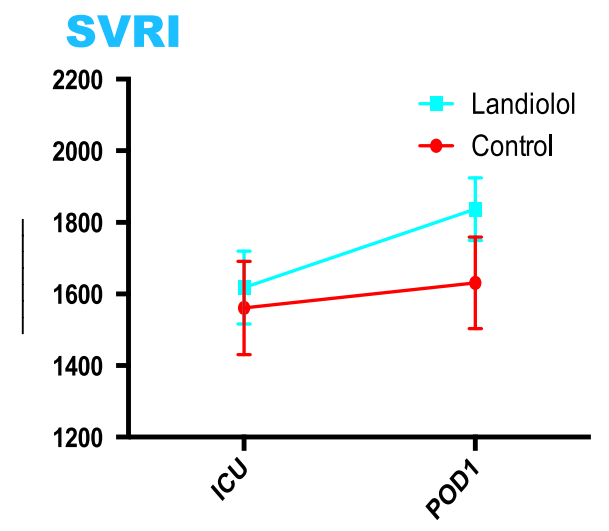

cardiac index, $H R$ heart rate, $I C U$ intensive care unit, $O P E$ intraoperative, $P O D 1$ postoperative day 1, SBP systolic blood pressure, $S V R I$ systemic vascular resistance index

devised. It is necessary, however, to increase the number of cases and to study outcomes during the follow-up period.

\section{LIMITATIONS}

There are some limitations associated with this study. First, our study was retrospective in nature and carried out at a single institution. The number of patients was small, because only isolated coronary surgery cases were selected. Because this drug has a very short half-life, an administration method that minimizes the occurrence of side effects should be developed. An anesthesiologist declined to use when hemodynamic 
Table 6 Relationships of various factors to postoperative atrial fibrillation

\begin{tabular}{llll}
\hline & AF+ $(\boldsymbol{n}=\mathbf{2 8})$ & AF- $(\boldsymbol{n}=\mathbf{8 8})$ & $\boldsymbol{P}$ value \\
\hline Mean age & $68.38 \pm 1.45$ & $67.93 \pm 0.99$ & 0.8235 \\
Age $>70$ years & $14(53.60 \%)$ & $42(47.70 \%)$ & 0.5938 \\
Female sex & $4(14.30 \%)$ & $14(15.90 \%)$ & 0.8380 \\
Body surface area & $1.64 \pm 0.03$ & $1.65 \pm 0.02$ & 0.7177 \\
OMI & $3(10.70 \%)$ & $18(20.50 \%)$ & 0.2474 \\
LVEF $(\%)$ & $58.91 \pm 2.87$ & $56.64 \pm 1.57$ & 0.3241 \\
Number of disease vessels & $2.73 \pm 0.10$ & $2.79 \pm 0.06$ & 0.6237 \\
Landiolol use & $5(17.90 \%)$ & $36(40.90 \%)$ & 0.0263 \\
$\beta$-Blocker & $5(17.90 \%)$ & $16(18.20 \%)$ & 0.9693 \\
\hline
\end{tabular}

Data presented as $n(\%)$ or mean \pm standard deviation

$A F+$ patients with postoperative atrial fibrillation, $A F-$ patients with no postoperative atrial fibrillation, $L V E F$ left ventricular ejection fraction, $O M I$ old myocardial infarction

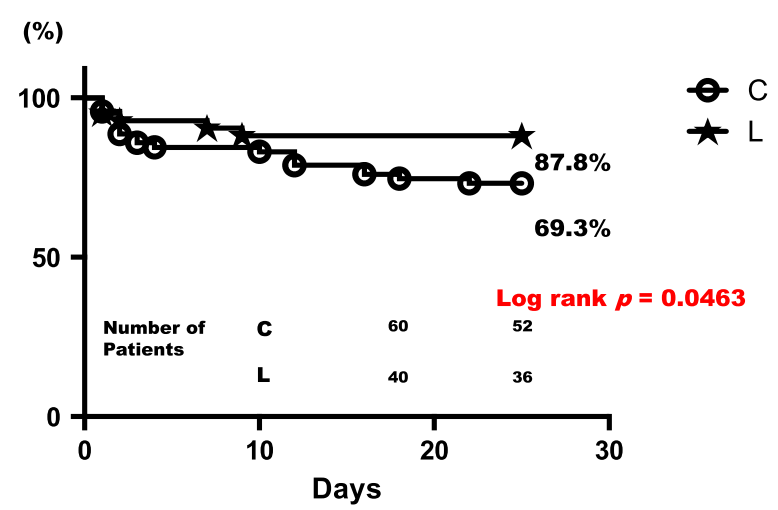

Fig. 2 Freedom from postoperative atrial fibrillation. $C$ control, $L$ landiolol

instability. The selection criterion for patients to be treated with landiolol is the choice of anesthesiologist, and was not recorded due to the study being retrospective. We consider landiolol to be safe when it is initiated at $2 \mu \mathrm{g} / \mathrm{kg} / \mathrm{min}$ intraoperatively, and we experienced no major complications with this method of administration. It will be important to carry out multi-center randomized controlled trials evaluating this rate of administration method in the future.

\section{CONCLUSION}

Landiolol, an ultrashort-acting $\beta 1$-selective blocker, has a preventive effect on the development of AF after CABG surgery and may achieve successful perioperative management of patients. To further these findings, we plan to conduct a randomized prospective study to investigate the inhibitory effects of intraoperative study landiolol on postoperative $\mathrm{AF}$ in patients who have undergone off-pump CABG.

\section{ACKNOWLEDGMENTS}

All authors had full access to all of the data in this study and take complete responsibility for the integrity of the data and accuracy of the data analysis. No funding or sponsorship was received for this study or publication of this article. All named authors meet the ICMJE criteria for authorship for this manuscript, take responsibility for the integrity of the work 
as a whole, and have given final approval for the version to be published.

Conflict of interest. M. Osumi, T. Tashiro, Y. Morita, S. Kamiya, N. Minematsu, M. Nishimi, and $\mathrm{H}$. Wada declare no conflict of interest.

Compliance with ethics guidelines. All procedures followed were in accordance with the ethical standards of the responsible committee on human experimentation (institutional and national) and with the Helsinki Declaration of 1975 , as revised in 2000 and 2008. Informed consent was obtained from all patients for being included in the study.

Open Access. This article is distributed under the terms of the Creative Commons Attribution Noncommercial License which permits any noncommercial use, distribution, and reproduction in any medium, provided the original author(s) and the source are credited.

\section{REFERENCES}

1. Mitchell LB. Incidence, timing and outcome of atrial tachyarrhythmia after cardiac surgery. In: Steinberg JS, editor. Atrial fibrillation after cardiac surgery. Boston: Kluwer Academic Publishers; 2000. p. $37-50$.

2. Hogue CW Jr, Creswell LL, Gutterman DD, Fleisher LA, American College of Chest Physicians. Epidemiology, mechanism, and risks: American College of Chest Physicians guidelines for the prevention and management of postoperative atrial fibrillation after cardiac surgery. Chest. 2005;128:9S-16S.

3. Mathew JP, Parks R, Savino JS, et al. Atrial fibrillation following coronary artery bypass surgery: predictors, outcomes, and resource utilization. JAMA. 1996;276:300-6.

4. Creswell LL, Schuessler RB, Rosenbloom M, Cox JL. Hazards of postoperative atrial arrhythmias. Ann Thorac Surg. 1993;56:539-49.
5. Aranki SF, Shaw DP, Adams DH, et al. Predictors of atrial fibrillation after coronary artery surgery. Current trends and impact on hospital resources. Circulation. 1996;94:390-7.

6. Martinez EA, Bass EB, Zimetbaum P, American College of Chest Physicians. Pharmacologic control of rhythm: American College Chest Physicians guidelines for the prevention and management of postoperative atrial fibrillation after cardiac surgery. Chest. 2005;128:48S-55S.

7. Fuster V, Ryden LE, Cannon DS, et al. 2011 ACCF/ AHA/HRS focused updates incorporated into the ACC/AHA/ESC 2006 Guidelines for the management of patients with atrial fibrillation: a report of the American College of Cardiology Foundation/American Heart Association Task Force on practice guidelines developed in partnership with the European Society of Cardiology and in partnership with the European Heart Rhythm Association and the Heart Rhythm Society. J Am Coll Cardiol. 2011;57:e101-98.

8. Nagaoka E, Arai H, Tamura K, et al. Prevention of atrial fibrillation with ultra-low dose landiolol after off-pump coronary artery bypass grafting. Ann Thorac Cardiovasc Surg. 2014;20:219-34.

9. Slogoff S, Keats AS. Does perioperative myocardial ischemia lead to postoperative myocardial infarction? Anesthesiology. 1985;62:107-14.

10. Atarashi H, Kuruma A, Yashima $M$, et al. Pharmacokinetics of landiolol hydrochloride, a new ultra-short-acting beta-blocker, in patients with cardiac arrhythmias. Clin Pharmacol Ther. 2000;68:143-50.

11. Roques F, Michel P, Goldstone AR, Nashef SAM. The logistic Euro SCORE. Eur Heart J. 2003;24:882-3.

12. Ito $\mathrm{H}$, Sobue $\mathrm{K}$, So $\mathrm{M}$, et al. Use of landiolol hydrochloride for perioperative management of supraventricular tachycardia. J Anesth. 2006;20:253-4.

13. Sezai A, Minami K, Nakai $T$, et al. Landiolol hydrochloride for prevention of atrial fibrillation after coronary artery bypass grafting: new evidence from the PASCAL trial. J Thorac Cardiovasc Surg. 2011;141:1478-87.

14. Sakamoto A, Kitazaka M, Takamoto S, Namiki A, Kasanuki H, Hosoda S. JL-KNIGHT study group. Landiolol an ultra-short-acting $\beta 1$-blocker, more effectively terminates atrial fibrillation than diltiazem after open heart surgery: prospective, multicenter, randomized, open-label study (JLKNIGHT study). Circ J. 2012;76:1097-101. 
15. Iguchi $S$, Iwamura $H$, Nishizaki $M$, et al. Development of a highly cardioselective ultra short-acting beta-blocker, ONO-1101. Chem Pharm Bull (Toyko). 1992;40:1462-9.

16. Motomura S, Hagihara A, Narumi Y, et al. Time course of a new ultrashort-acting betaadrenoceptor-blocking drug, ONO-1101: comparison with those of esmolol and propranolol by using the canine isolated, bloodperfused heart preparations. J Cardiovasc Pharmacol. 1998;31:431-40.

17. Muraki K, Nakagawa H, Nagano N, et al. Effects of ONO-1101, a novel beta-antagonist, on action potential and membrane currents in cardiac muscle. J Pharmacol Exp Ther. 1996;278:555-63.

18. Sugiyama A, Takahara A, Hashimoto K. Electrophysiologic cardiohemodynamic and betablocking actions of a new ultrashort-acting betablocker, ONO-1101, assessed by the in vivo canine model in comparison with esmolol. J Cardiovasc Pharmacol. 1999;34:70-7.
19. Katoh T, Ohara T, Ogawa S, et al. Multicenter survey on the validity of the CD-ROM guideline for antiarrhythmic drug therapy produced by the Japanese Circulation Society and Japanese Society on Electrocardiology: preliminary report of the survey of the Japanese guideline for Arrhythmia Management By Individual Therapy (J-GAMBIT). Circ J. 2005;69:1357-60.

20. Almassi GH, Sommers T, Moritz TE, et al. Stroke in cardiac surgical patients: determinants and outcome. Ann Thorac Surg. 1999;68:391-7.

21. Giri S, White CM, Dunn AB, et al. Oral amiodarone for prevention of atrial fibrillation after open heart surgery, the Atrial Fibrillation Suppression Trial (AFIST): a randomized placebo-controlled trial. Lancet. 2001;357:830-6.

22. Gomes JA, Ip J, Santoni-Rugiu F, et al. Oral $\mathrm{D}, \mathrm{L}$ sotalol reduces the incidence of postoperative atrial fibrillation in coronary artery bypass surgery patients: a randomized, double-blind, placebocontrolled study. J Am Coll Cardiol. 1999;34:334-9. 